\title{
Design a control system for observing vibration and temperature of turbines
}

\author{
Omar Farhan Al-Hardanee ${ }^{1}$, İlyas Çankaya ${ }^{2}$, Abdulmuttalib A. Muhsen ${ }^{3}$, Huseyin Canbolat ${ }^{4}$ \\ ${ }^{1}$ Department of Electrical and Electronics Engineering, Karabuk University, Karabuk, Turkey \\ ${ }^{1,2,4}$ Department of Electrical and Electronics Engineering, Ankara Yildirim Beyazit University, Ankara, Turkey \\ ${ }^{3}$ Faculty of Power and Aeronautical Engineering, Warsaw University of Technology, Warsaw, Poland \\ ${ }^{1,3}$ Haditha Hydropower Station, Ministry of Electricity, Haditha, Iraq
}

\section{Article Info \\ Article history: \\ Received Dec 19, 2020 \\ Revised Oct 8, 2021 \\ Accepted Oct 15, 2021 \\ Keywords: \\ MATLAB GUI \\ Monitoring system \\ Temperature \\ Turbine \\ Vibration}

\section{Corresponding Author:}

Omar Farhan Al-Hardanee

Department of Electrical and Electronics Engineering, Karabuk University

Karabuk, Turkey

Email: omar.f.alhardanee@gmail.com

\begin{abstract}
The core of a typical hydroelectric power plant is the turbine. Vibration and overheating in a turbine occur when water flows through it, and with increased vibration and high temperature, it will cause the turbine blade to break. In this study, the control and monitoring system is designed to predict and avoid any error before it occurs. This process is achieved by measuring vibration and temperature using sensors and sending signals through the Arduino to the graphical user interfaces (GUI), the system compares the signals taken from the sensors with the permissible limits, and when the permissible limits are exceeded, the processor takes appropriate measures to open and close the turbine gates, where the data is displayed in matrix laboratory graphical user interfaces (MATLAB's GUI) screen. In this way, monitoring is done, and the appropriate action are taken to avoid mistakes.
\end{abstract}

This is an open access article under the CC BY-SA license.

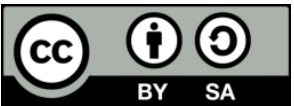

\section{INTRODUCTION}

Dam is one of the main power resources in the world. With population expansion, the demand for electric power is increasing, to cover this increase, the generating units operate at maximum power and in very severe operating conditions, as the turbines operate for a long period (almost every year). These bad operating conditions make the turbines subject to a severe level of vibration and temperature in the structure due to the high dynamic loading and due to severe vortex in the flow passage as well, which leads to extremely high corrosion in all turbine components, especially the runner blades due to the high bore level as in the turbines located in Haditha Dam, as seen in Figure 1 [1].

Haditha dam is the only source of power generation in the western regions of Iraq, it consist of six units (Kaplan Turbines), each of them generating $110 \mathrm{MW}$, the station was put to work and begin operating in 1986. Unit No.2 suffers from serious cracks in the runner blades and also suffers in addition to the remaining units from severe cavity erosion which causes increased vibration as shown in Figure 2 [1], [2]. Any problem will cause a feather crash, it is a tragic accident in terms of material losses, time and power outages for the population, these are the main problems that should be avoided. For that, the program is designed to predict any error and take appropriate measures to avoid it.

Both Zhong Liu and Lihua Zhou assumed a control system to observe the vibration in hydraulic turbines and display the vibration wave, based on LabVIEW system was proposed [3]. Rati Mohanta at all, 
the causes of vibrations on rotary and non-rotary equipment for hydraulic turbines were discussed together with vibration measurement standards and provided a summary of studies from 30 years [4]. Delphin Technology provided the vibration monitoring system, where Femaris supplied its own system to assist as a vibration monitoring system for hydro turbines, software used for fault diagnostics are ProfiSignal Basic and ProfiSignal Vibro [5]. Vijaya and Surender used a robot to monitor temperature and smoke. In industrial uses and displayed in MATLAB GUI [6]. Puneet Bansal, and Rajay Vedaraj proposed a vibration monitoring system on an electrical motor using MATLAB GUI [7].

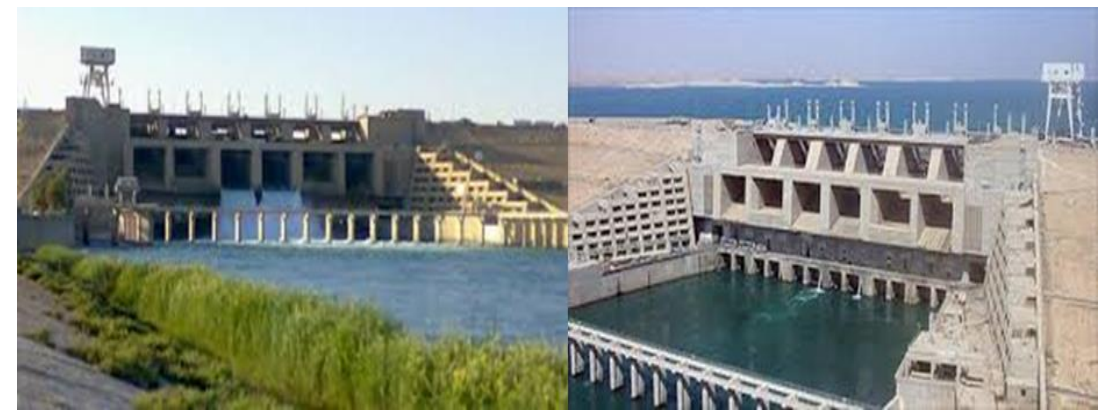

Figure 1. Haditha dam

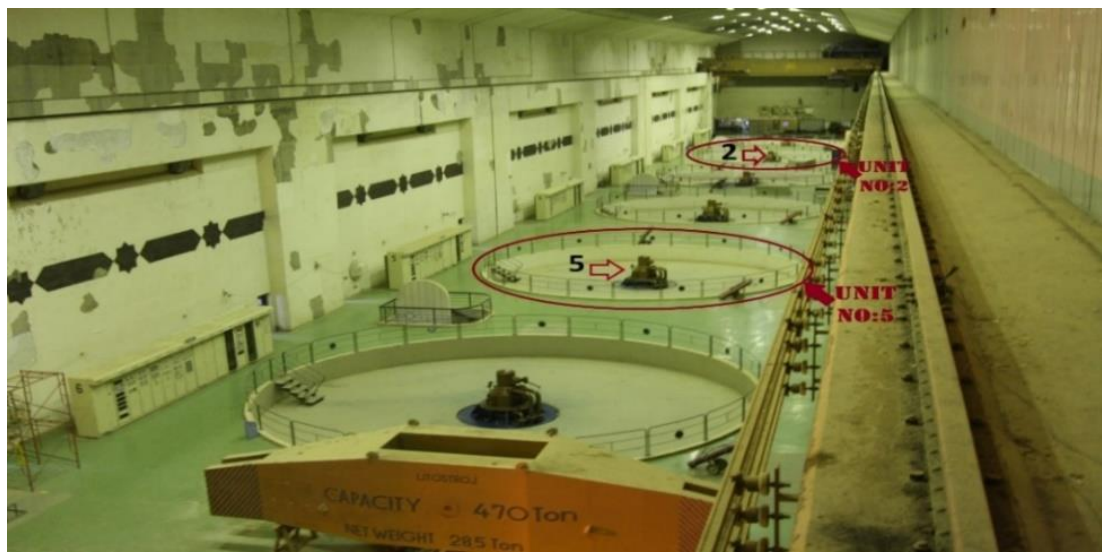

Figure 2. The powerhouse of Haditha dam

Previous studies provided individual solutions for monitoring vibration or temperature. In this study, vibration and temperature monitoring will be performed for the hydroelectric turbines; these signals are then drawn into the GUI in Matlab, which takes its data from sensors that are connected with Arduino, based on data previously entered by the observer and compared to the signals received from the sensors, appropriate decisions can be taken to avoid damage to the turbines [8], [9]. The remainder of this paper is organized as follows: section 2 includes information about the turbines problem, diagnose temperature fault, diagnose vibration fault, system architecture and methodology (this section includes the graphical user interface, the proposed control system, how it works, and how it is installed). Section 3 presents and discusses the results. Finally, in section 4 it is presented the conclusion of this work.

\section{MATERAIL AND METHODS}

\subsection{Hydro turbine efficiency}

The Turbines efficiency indirectly reflects its working condition; when hydraulic turbines operate under operational conditions outside design or when turbines become old, so their work becomes degraded, their performance in the energy field will change and fall towards the negative indicator of their performance, In the event of high dynamic load of turbines it causes severe erosion in the cavity and the occurrence of high vibration, and this will cause the collapse of feathers, a tragic accident in terms of material losses and time and power cuts to the populations are the main problems which should be monitored to improve the efficiency of turbines and Its perfect performance [1], [10], [11]. 


\subsection{Diagnosis of temperature and fault and vibration faults}

The vibration in the turbines is accompanied by a temperature caused by the same cause of vibration. Which are the bubbles that enter with the water into the turbine [1]. Also, the vibration of the motor is classified as mechanical, aerodynamic, and electromagnetic [12], [13].

\subsubsection{Mechanical vibration}

The turbines status are evaluated on the basis of several factors, such as information obtained from the turbine's observing system, design characteristics, quantities and pressure of water flowing to it, and maintenance records and repair of faults in turbines and the tables specified by the company to carry turbines for various factors such as pressure and temperature, where all these data are brought into smart strategies and algorithms to predict the error before occurs, the situation and determine the situation of each turbine in the dam and identify the affected unit to facilitate the maintenance if needed. There are other causes of vibrations such as aerodynamic and electromagnetic [10], [14], [15].

\subsubsection{Aerodynamic vibration}

Aerodynamic problems are due to discrete blade passing frequencies, Resonant volume excitations within motor, Ventilation fans and Broadband turbulence. The aerodynamic component caused by the rotation of the blades It is often dominated on a combination of skeletal and aerobic seizures (Aeroelastic damping). Vibrations related to electrical faults are due to imbalanced electromagnetic forces on the rotor and stator. This imbalance is due to air gap eccentricity, broken rotor bars, unequal distribution of air gap flux, inter-turn faults, shorted or open stator and rotor windings, unequal phase currents, magnetostriction and oscillations of torque [16], [17].

\subsubsection{Electromagnetic vibration}

Electrical defects and faults in the generators also cause vibration in the associated turbines by it, because of the unbalanced magnetic forces on the fixed and rotary, where this imbalance results because the air gap, the air gap is distributed unevenly, reflection faults, unequal phase current, the fluctuation of torque due to magnetism [9]. And The relation between electrical supply frequency and rotational frequenc [18]. This leads to an occurrence cavity in the feathers as shown in Figure 3 [19]-[21].

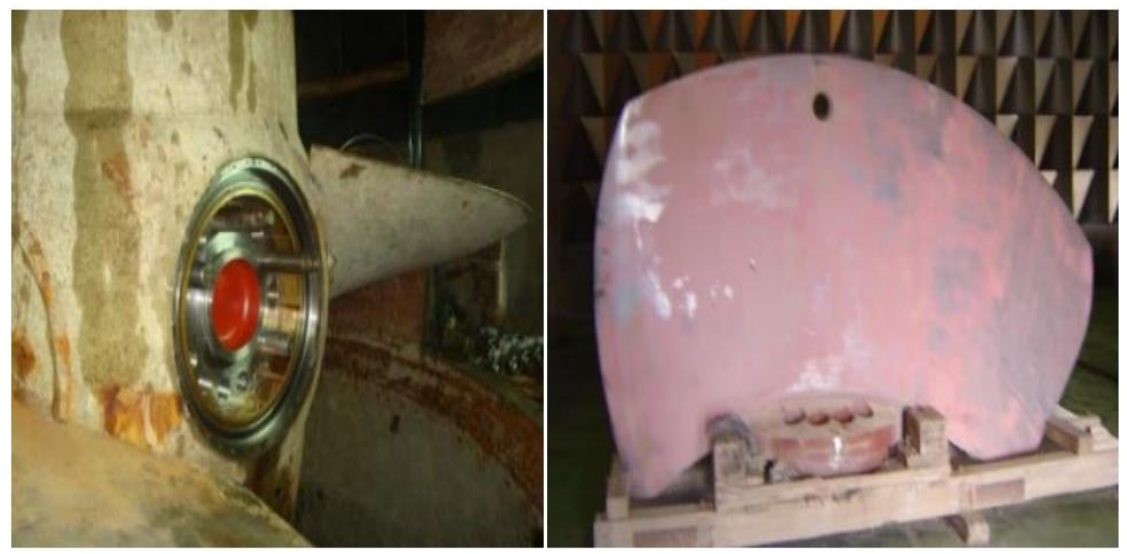

Figure 3. Francis turbine cavitation damage [22]

\subsection{System architecture}

Based on changing the temperature and vibration of turbines and variable products that may reach the risk stage in any moment, a control system must be available that can handle all the situations. Therefore, the control system is designed as shown in Figures 4 and 5, illustrate the system work mechanism and the flexibility. The initialization of the hardware acquisition is dawn firstly, then the four sensors ( 2 temperature and 2 vibration) start to aggregate data and send them to the Arduino in order to start pre-processing data, and depending on that, there are two possibilities. The first possibility is the maximum danger, send a signal to turn on the alarm, and close the turbine gate to stop the vibration. The second possibility is the non-hazardous condition, where the data is sent to the computer to be analyzed through the MATLAB program, through which the system is monitored by drawing the temperature and vibration signal using GUI, and based on it there are two possibilities: i) The first case is the natural situation, where the system will measure the vibration 
and temperature again; and ii) The second case is a non-max danger situation, where the signal will be sent to trigger the alarm and give control to the observer who can close and open the gates of the turbines, and then re-process to measure the vibration and temperature again and monitor changes. Minimum risk dangerous: i) The dangerous vibration state of turbine is $5 \mathrm{~mm} / \mathrm{s}$ [17]; and ii) The dangerous temperature state of turbine $80 \mathrm{C}^{\circ}$ [17]. The alarm devices are placed in the control unit of the generation unit in the machinery room as well as the central control room.

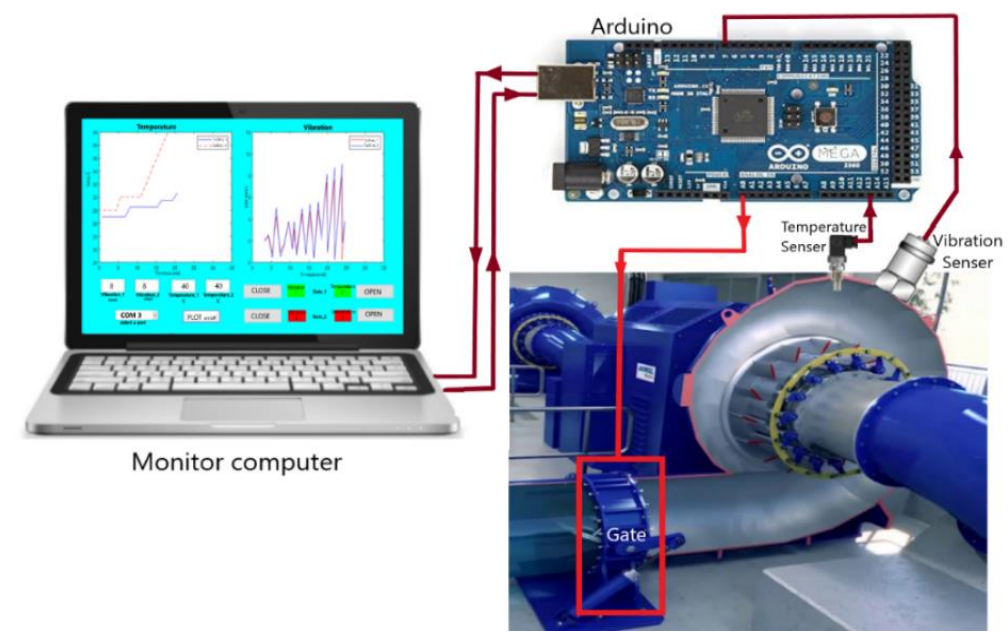

Figure 4. System architecture

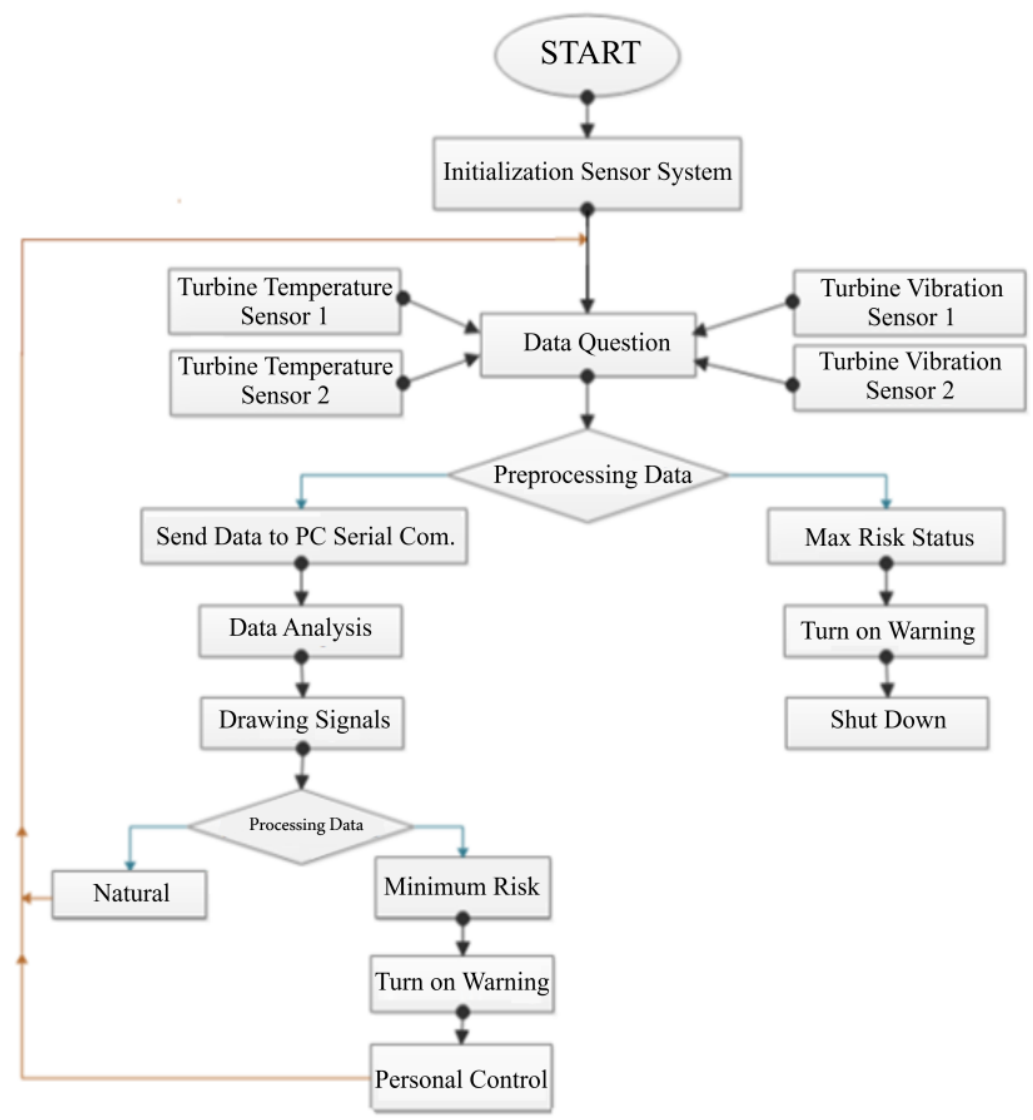

Figure 5. Flowchart of the monitoring system 
The gates are opened and closed based on fixed rules depends on the signal sent by the MATLAB or through pre-processing in the Arduino. Dangerous situations are determined based on the information provided by the turbine manufacturers as shown in Table 1 . As the Table 1 shows the strategy of how the system works, as it indicates when the gates open and when they close, based on the condition of the vibrations and the temperature.

Table 1. Rules of opening and closing gates

\begin{tabular}{cccccc}
\hline Turbine & Dec & Chr & Sensor & Status & Gate \\
\hline 1 & 48 & 0 & Temp. or Vib. & Risk & Close \\
1 & 49 & 1 & Temp. or Vib. & Natural & Open \\
2 & 50 & 2 & Temp. or Vib. & Risk & Close \\
2 & 51 & 3 & Temp. or Vib. & Natural & Open \\
\hline
\end{tabular}

\subsection{Methodology}

The proposed monitoring system basically consists of two parts: the hardware part (acquisition unit) which consists of data acquisition unit-based on Arduino MEGA2560 board and different types of digital and analogue sensors such as temperature and vibration sensors as shows in Figure 6. While the other part is based on MATLAB GUI in order to control and draw the acquisition data that are coming from hardware unit. Monitoring the vibration and temperature for the turbines system needs to plot the real time use of the vibration and temperature, for those needs to measure the analog voltage signal from the vibration sensors, and digital voltage signal from the temperature sensors installed on the specific location on turbine body as demonstrated in Figure 6 . Depending on the place, which was adopted by the company established for the turbines) [23]. The hardware part of our system was tested by using Arduino and two different external sensors, (vibration and temperature) which can give variable value like the mentioned in the hardware part like it is presented in Figure 7 and give this voltage to the Arduino which is connected to MATLAB.

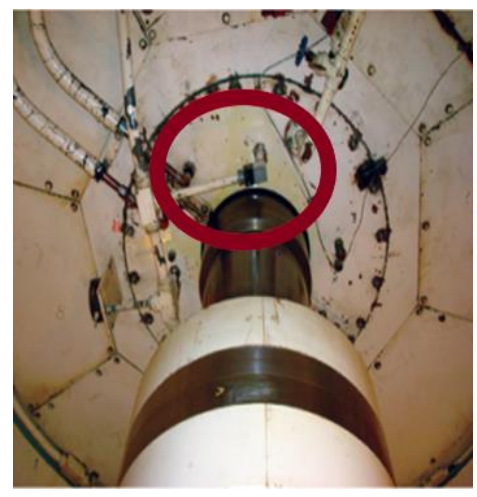

Figure 6. Location of sensors

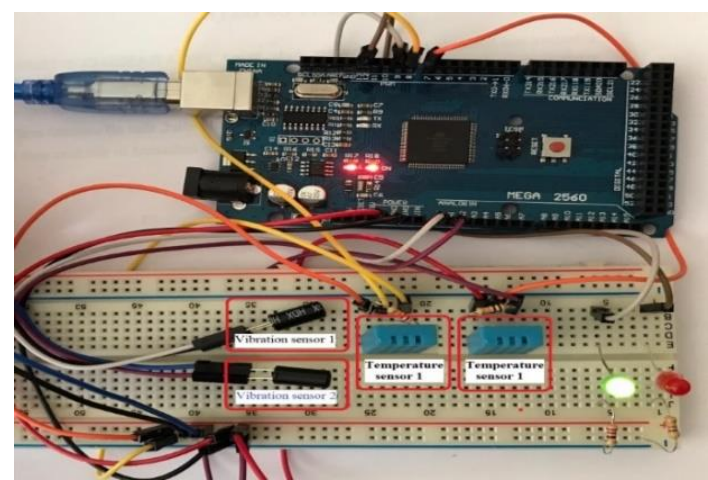

Figure 7. Control circuit

The MATLAB includes graphical user interfaces that display the temperature and vibration schemes, and the buttons through which some actions are taken such as reducing the amount of water flowing or shutting the turbine's gates completely, so the sensors must be connected to the Arduino and connect the Arduino circuit to the computer by the serial connection [24]. Where the gates are connected to the Arduino controller by electrical devices such as the relays and the contactors, and based on the signals measured by the sensors, a decision is taken to open and close the gates, where each signal is processed separately and compared with the signal specified as the beginning of the danger stage by the processor, as shown in Figure 8 [25].

\section{RESULTS}

The GUI is designed for two purposes, the first is to draw the vibration and temperature signal, and the second is to control the opening and closing of the water flow gate to the turbine, as shown in Figure 8. The GUI includes two graphical windows. The first graphical window shows the results of vibration for the turbines, and the 
second graphical window shows the results of temperature for the turbines. For the control section, GUI includes user accessibility to open and close the dam gates, through the buttons on the screen to facilitate user work.

The user starts from the pop-up: i) Step 1, where the portal used is chosen to facilitate access process. Then the minimum values for the vibrations and temperatures can be written by the user in four boxes (vibration1, vibration2, temperature1 and temperature2); ii) Step 2, these are the threshold values from which danger situations begin, and based on it, appropriate decisions are taken, such as sending a warning signal or closing the gates; iii) Step 3 is to click on the graph button (PLOT), where it starts with the graph, and the graph will be stop by pressing on the same button; and iv) Step 4, The GUI includes four color boxes that show the status of the sensors, where each sensor is linked to a square of colors, in the normal case it will be green and in the case of danger it will be red, and four buttons to open and close the gates, as shown in 4th panel [26].

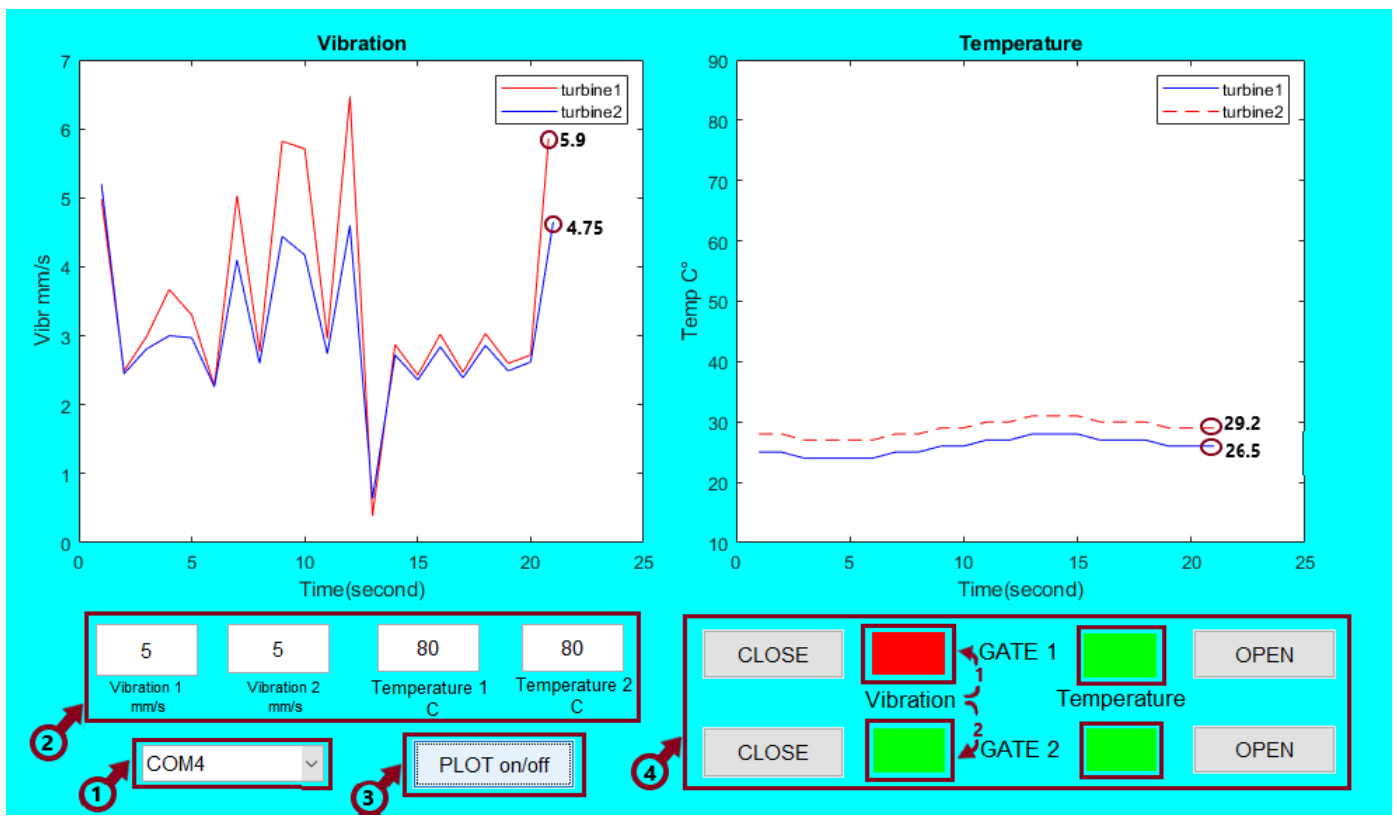

Figure 8. GUI for monitoring system

The controller is programmed for two tasks: i) The first is to track the vibration and temperature signal through the sensors and transmit it to be displayed in the graphical user interface; and ii) The second is to control the opening and closing of the gates, where the decision is made in two ways, the first is through the controller, and the second is through the observer. The decision is taken by the controller in the case of extreme danger, where the vibration or temperature suddenly rises and the maximum danger stage that is determined by the programmer is exceeded, the decision is taken to turn on the alarm and close the gate to cut off the flow of water to the turbine and prevent any damage such as breaking the runner blades. Except for the danger stage, the control is done by the observer, who has the freedom to decide to open and close the gates, whether in the danger stage or otherwise. If the vibration or temperature reaches the limit set by the user, the alarm device turns on to alert the observer to take the appropriate action in case the signal rises more and more, through the buttons installed in the graphical user interface.

The results of this project are represented in two models as shown in Figures 8 and 9. The first model, shown in Figure 8, where exceeding the vibration of the first turbine represents the threshold of danger, so the red light shows this situation and then the alarm starts to work, and the decision is made according to what was mentioned in the section 2.3. The second model is represented in Figure 9. It shows that the vibration and temperature exceeded the danger threshold for the second turbine, and this shows the appearance of their signal indicators and the appearance of the two-colored boxes of the second turbine in red.

The Table 2 shows an analysis of the results of the first model, by comparing the current value of vibration and temperature with the threshold value for each of them, we find that the vibration value of the first turbine has exceeded the threshold, therefore, it is in a state of danger, and this condition is clearly shown by the appearance of its color box in red. As for the remaining values, they are below the threshold, so they are in the normal state, as the color boxes appear in green. The Table 3 shows an analysis of the results of the second model. Where it shows two different cases for these turbines. The value of the vibration and the 
temperature of the first turbine are below the threshold, so they are in the normal state. This condition is clearly shown by the appearance of their two-color boxes in green. Furthermore, the value of vibration and temperature of the second turbine has exceeded the threshold, so it is a danger state. When this situation occurs, the color boxes will be red.

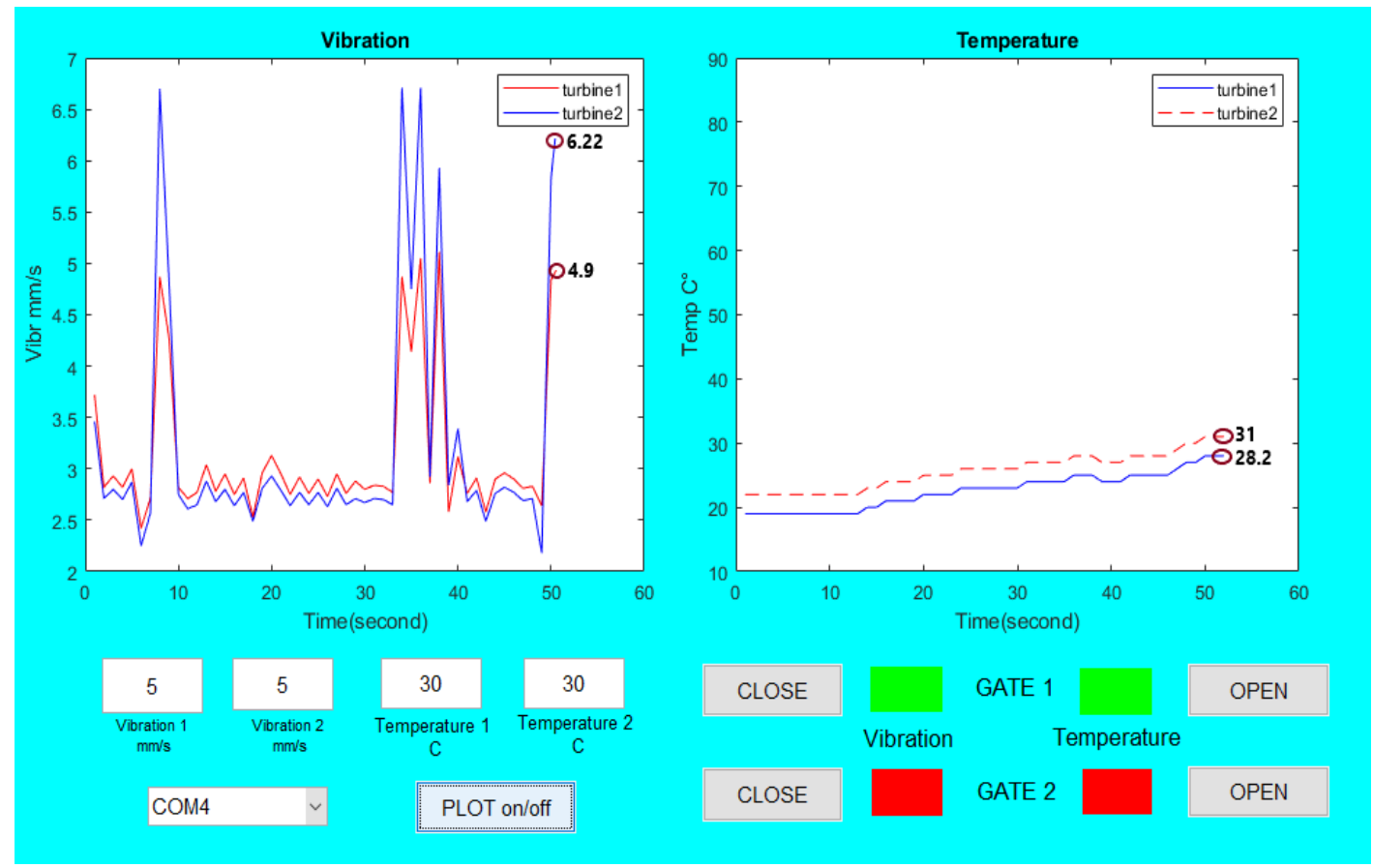

Figure 9. GUI for monitoring system

Table 2. Rules for the first model

\begin{tabular}{clcccc}
\hline Turbine & Sensor & Threshold & Current & Color & Status \\
\hline 1 & Vibration_1 & 5 & 5.9 & Red & Risk \\
2 & Vibration_2 & 5 & 4.75 & Green & Natural \\
1 & Temperature_1 & 80 & 29.2 & Green & Natural \\
2 & Temperature_2 & 80 & 26.5 & Green & Natural \\
\hline
\end{tabular}

Table 3. Rules for the second model

\begin{tabular}{clcccc}
\hline Turbine & Sensor & Threshold & Current & Color & Status \\
\hline 1 & Vibration_1 & 5 & 4.9 & Green & Natural \\
2 & Vibration_2 & 5 & 6.22 & Red & Risk \\
1 & Temperature_1 & 30 & 28.2 & Green & Natural \\
2 & Temperature_2 & 30 & 31 & Red & Risk \\
\hline
\end{tabular}

\section{CONCLUSION AND FUTURE WORK}

The GUI is designed for a monitoring and control system, for turbines using vibration and temperature sensors with Arduino to predict any defect or risk situation and take appropriate action to avoid the breakdown of dam turbine blades. It is monitoring the status of the turbines continuously, by displaying the graph for the temperature and vibrations in the GUI and save the data. To avoid the loss of money and time and power cuts to the population and do not need to call a private company. For the future work, this program can be developed by adding vibration sensors to monitor the spindle, developing the graphical user interface to include a third screen showing the vibration signal for the spindle, and development the control panel to proper this addition.

\section{REFERENCES}

[1] A. A. Muhsen, G. Szymański, T. Mankhi, and B. Attiya, "Selecting the most efficient maintenance approach using AHP multiple criteria decision making at haditha hydropower plant," Zesz. Nauk. Politech. Poznańskiej. Organ. $i$ Zarzadzanie, vol. 78, no. 78, pp. 113-136, 2018, doi: 10.21008/j.0239-9415.2018.078.09.

Design a control system for observing vibration and temperature of turbines (Omar Farhan Al-Hardanee) 
[2] A.-Hardanee and O. Farhan, "Design and Improvement of an Intelligent Control System to Solve the Dam Ground Water Problem," Diss. Ankara Yıldırım Beyazıt Üniversitesi Fen Bilimleri Enstitüsü, 2019.

[3] Z. Liu, S. Zou, and L. Zhou, "Condition Monitoring System for Hydro Turbines Based on LabVIEW," 2012 AsiaPacific Power and Energy Engineering Conference, 2012, pp. 1-4, doi: 10.1109/APPEEC.2012.6306997.

[4] Z. Liu, S. Zou, and L. Zhou, "Condition monitoring system for hydro turbines based on LabVIEW," Asia-Pacific Power Energy Eng. Conf. APPEEC, 2012, pp. 0-3, doi: 10.1109/APPEEC.2012.6306997.

[5] R. K. Mohanta, T. R. Chelliah, S. Allamsetty, A. Akula, and R. Ghosh, "Sources of vibration and their treatment in hydro power stations-A review," Eng. Sci. Technol. an Int. J., vol. 20, no. 2, pp. 637-648, 2017, doi: 10.1016/j.jestch.2016.11.004.

[6] D. Technology, C. A. S. Dataloggers, A. Note, H. Sa, H. O. Sa, and H. Turbines, "Vibration Monitoring System for Hydro Turbines," pp. 1-5, 2018.

[7] K. K. Vijaya and S. Surender, "Industry Monitoring Robot using Arduino Uno with Matlab Interface," Adv. Robot. Autom., vol. 05, no. 02, pp. 2-4, 2016, doi: 10.4172/2168-9695.1000150.

[8] P. Bansal and I. S. R. Vedaraj, "Monitoring and Analysis of Vibration Signal in Machine Tool Structures," Int. J. Eng. Dev. Res., vol. 2, no. 2, pp. 2310-2317, 2014.

[9] R. Mohanty, "Machinery condition monitoring: Principles and practices," CRC Press, 2014.

[10] K. H. Aronsen, "An experimental investigation of in-line and combined in-line and cross-flow vortex induced vibrations," Norwegian University of Science and Technology 2007.

[11] D. Jiang et al., "Water-solid triboelectric nanogenerators: An alternative means for harvesting hydropower," Renew. Sustain. Energy Rev., vol. 115, no. August, p. 109366, 2019, doi: 10.1016/j.rser.2019.109366.

[12] Y.-D. Choi, J.-I. Lim, Y.-T. Kim and Y.-H. Lee, "Performance and Internal Flow Characteristics of a Cross-Flow Hydro Turbine by the Shapes of Nozzle and Runner Blade," J. Fluid Sci. Technol., vol. 3, no. 3, pp. 398-409, 2008, doi: 10.1299/jfst.3.398.

[13] C. E. Brennen, "Hydrodynamics of pumps," Cambridge University Press, 2011.

[14] H. Xue, H. Wang, P. Chen, K. Li, and L. Song, "Automatic diagnosis method for structural fault of rotating machinery based on distinctive frequency components and support vector machines under varied operating conditions," Neurocomputing, vol. 116, pp. 326-335, 2013, doi: 10.1016/j.neucom.2012.02.048.

[15] A. Staino and B. Basu, "Dynamics and control of vibrations in wind turbines with variable rotor speed," Eng. Struct., vol. 56, pp. 58-67, 2013, doi: 10.1016/j.engstruct.2013.03.014.

[16] T. A. Mankhi, S. Legutko, J. H. Al-Bedhany, and A. A. Muhsen, "Selecting the Most Efficient Bearing of Wind Turbine Gearbox Using (Analytical Hierarchy Process) Method 'aHP,” IOP Conf. Ser. Mater. Sci. Eng., vol. 518, no. 3, 2019, doi: 10.1088/1757-899X/518/3/032050.

[17] A. Bobat, "Thermal pollution caused by hydropower plants," in Energy systems and management, Springer, 2015, pp. 19-32, 2015, doi: 10.1007/978-3-319-16024-5_2.

[18] S. Nandi, H. A. Toliyat, and X. Li, "Condition monitoring and fault diagnosis of electrical motors - A review," IEEE Trans. Energy Convers., vol. 20, no. 4, pp. 719-729, 2005, doi: 10.1109/TEC.2005.847955.

[19] K. Wang, "Vibration Monitoring on electrical machine using Vold-Kalman Filter Order Tracking Master of Science in the Department of Mechanical and Aeronautical Vibration Monitoring on electrical machine using VoldKalman Filter Order Tracking by," Built Environ., 2008.

[20] N. A. Londono, "Use of vibration data for structural health monitoring of bridges of bridges," Heritage Branch, 2006.

[21] Brennen CE. Cavitation and bubble dynamics. Cambridge University Press; 2014.

[22] A. A. Muhsen, A. A. Al-Malik, B. H. Attiya, O. F. Al-Hardanee, and K. A. Abdalazize, "Modal analysis of Kaplan turbine in Haditha hydropower plant using ANSYS and SolidWorks," In IOP Conference Series: Materials Science and Engineering, vol. 1105, no. 1, p. 012056. IOP Publishing, 2021, doi: 10.1088/1757-899X/1105/1/012056.

[23] P. T. K. Østby, J. T. Billdal, K. Sivertsen, B. Haugen and O. G. Dahlhaug, "Dynamic Stresses In High Head Francis Turbines," Int. J. Hydropower Dams, vol. 23, no. 3, pp. 88-92, 2016.

[24] V. S. Pamulapati, Y. S. Rohan, V. S. A. I. Kiran, S. Sandeep and M. S. Rao, "Real-time Face Tracking using MATLAB and Arduino," vol. 1, no. 8, pp. 59-62, 2018.

[25] Fadzlina Naim, H. I. M. Zaini, S. S. Sarnin and N Ya'acob, "Interactive Learning Software for Engineering Subjects Based on MATLAB-GUI," vol. 8, no. 6, pp. 77-81, 1843, doi: 10.4314/jfas.v9i5s.19.

[26] S. R. Kumar, P. Raja and M. P. Selvan, "Virtual laboratory environment using MATLAB-GUI for teaching of induction generators," in 2012 Annual IEEE India Conference (INDICON), 2012, pp. 676-681, doi: 10.1109/INDCON.2012.6420703. 